\title{
Mercado de arte e divisão social do trabalho no século 19: o caso de Vincent van Gogh
}

\section{Felipe Sevilhano Martinez ${ }^{1}$}

Resumo: Este artigo trata de algumas características do mercado de arte do século 19, tais como a promoção da personalidade artística e a ausência de uma colocação bem definida para os artistas na divisão social do trabalho. A partir da carreira e da obra do pintor holandês Vincent van Gogh e das conferências sobre Economia Política da Arte de John Ruskin, argumentarei que a negação do caráter comercial do mercado de arte e o status do artista na sociedade capitalista são elementos fundamentais para o fortalecimento do próprio mercado.

Palavras-chave: mercado de arte, Van Gogh, Courbet, John Ruskin

\section{Art market and social division of labor in the nineteenth century: the case of Vincent van Gogh}

\begin{abstract}
This article addresses some of the characteristics of the nineteenth century art market, such as the promotion of artists' biographies and the absence of a well-defined position for the artist in the social division of labor. Based on the biography of the Dutch painter Vincent van Gogh and on the lectures on Political Economy of Art by John Ruskin, I intend to show that the artists' status in the industrial age and the denial of the commercial character of the art market are key elements to strengthen this market.
\end{abstract}

Keywords: art market, Van Gogh, Courbet, John Ruskin

1 Doutor em história da arte pela Unicamp. Defendeu mestrado sobre as obras de Vincent van Gogh no acervo do MASP, onde também trabalhou como pesquisador bolsista. Fez estágio doutoral no RKD - Nederlands Instituut voor Kunstgeschiedenis e no Museu Van Gogh, ambos na Holanda. É professor da Escola do MASP e dos cursos do MAM de São Paulo. Universidade Estadual de Campinas (UNICAMP) e Museu de Arte de São Paulo Assis Chateaubriand (MASP). E-mail: felipesmartinez@gmail.com. ORCID: https://orcid.org/0000-0002-8330-1807. Lattes iD: http:// lattes.cnpq.br/0536394960772726. São Paulo, Brasil 


\section{Breve panorama do mercado de arte do século 19}

O mercado de arte do século 19 nasceu em estreita associação com o sistema financeiro. A disponibilidade de crédito nas principais economias da época permitiu que os atores desse mercado desenvolvessem práticas comerciais até então desconhecidas nos negócios artísticos. No contexto francês, nomes como Paul Durand-Ruel e Georges Petit foram capazes de criar uma estrutura de produção e comercialização de obras de arte, a partir das pinturas dos artistas da chamada Escola de Barbizon, que serviriam como modelo para as gerações posteriores. A atuação desses marchands envolvia práticas comerciais, como a formação de estoques para controlar preços e lances artificiais em leilões, dentro do impulso da consolidação do sistema financeiro francês das décadas de 1860 e $1870^{1}$.

No plano do discurso, prevalecia a promoção das personalidades e da biografia dos artistas, de modo que a mercadoria a ser vendida passou a ser mais a personalidade do artista do que as obras por ele produzidas. Como será detalhado adiante, esse processo ocorreu por meio da associação entre marchands, críticos e escritores na promoção das biografias de artistas como Jean-François Millet, Théodore Rousseau e Bastien-Lepage, no contexto dka expansão do mercado de pintores paisagistas de meados do século. Além disso, os próprios marchands enobreciam suas trajetórias, como fez Durand-Ruel em suas memórias, nas quais fez questão de deixar claro que "odiava o comércio"2". Em outras palavras, embora este mercado movimentasse altos valores e operasse em estreita associação com o mundo financeiro, procurava manter uma distância higienizadora do comércio.

O comercialismo era uma espécie de estigma do qual toda arte que se pretendia verdadeira devia fugir. Em razão de uma exposição do pintor holandês Vincent van Gogh, realizada em Amsterdã em 1893, o crítico e pintor simbolista R. N. Roland Host escreveu que "a obra de arte tornou-se uma mercadoria tão boa quanto qualquer outra para especulação" e acrescentou que "aquela exposição era destinada às poucas pessoas que ainda acre-

1 A esse respeito, ver Green, Nicholas. Dealing in Temperaments: Economic Transformation of the Artistic Field in France during the Second Half of the Nineteenth Century. Art History, 10, março, 1987.

2 Durand-Ruel, Paul; Durand-Ruel, Flavie. Paul Durand-Ruel: memoirs of the first impressionist art dealer. Paris: Flammarion, 2014, p. 6. 
ditam que o que é imediatamente entendido nem sempre é o melhor"3. A declaração de Host traz dois elementos importantes: separa a alta arte do comércio vulgar e distingue aqueles que apreciam a arte verdadeiramente daqueles que se deixam levar pelo conteúdo fácil, vendável.

Teor semelhante pode ser encontrado em um célebre relato feito por Jean-Auguste Dominique Ingres, anos antes, condenando o comercialismo do Salão4: "o Salão asfixia e corrompe o sentimento do grandioso e do belo; os artistas são levados a expor ali pelas atrações e pela suposta boa sorte de um tema excêntrico que seja capaz de produzir algum efeito e levar a uma venda substancial. Assim, o Salão é, literalmente, apenas uma loja de quadros, um bazar no qual a enorme quantidade de objetos é avassaladora e onde reinam os negócios, não a arte". Aqui, a crítica ao Salão vem de um acadêmico maior, muito distante da modernidade de van Gogh, mas assim como na frase anterior, a arte dita elevada é contraposta ao baixo comércio, que envolve obras fáceis, capazes de produzir "algum efeito". Por caminhos diferentes, Host e Ingres parecem concordar que os adjetivos fácil e comercial andam lado a lado.

Em Ingres, o apreciador ideal é aquele versado nos temas da tradição e capaz de apreciar os critérios do belo clássico. Em Host, é aquele que entende que o valor de uma obra de arte demanda esforço, compreensão e nem sempre está evidente ${ }^{5}$. Nos dois casos, exige-se uma educação que diferencia o iniciado do apreciador vulgar. Ora, esse apreciador vulgar, que não é capaz de olhar nem a obra de Ingres, nem a obra de van Gogh, é ninguém menos do que o comprador médio que frequentava galerias e o Salão em busca das imagens, consideradas comerciais e apelativas, de Bouguereau ou Cabanel. Indesejável nas duas visões, ainda que tenha sido por causa dele que o mercado tenha podido se desenvolver. Um cliente anônimo, quase abstrato, do qual todos dependem e que está por toda parte, mas que ninguém é capaz de nomear. Fica, porém, uma pergunta: se a educação do público para uma pintura de Ingres passa pelos temas da

3 L'Exposition Van Gogh in Amsterdam, L'Art Moderne, 13, 1 de janeiro de 1893.

4 Retirado de Rewald, John. Theo van Gogh as Art Dealer. In: Studies on Post-Impressionism. Londres: Thames and Hudson, 1986.

5 No mesmo sentido, em 1910, Roger Fry, na famosa exposição na Grafton Galleries que tratou de Manet até o chamado de pós-impressionismo, declarou que seria necessária uma educação estética para apreciar as obras expostas. Ver introdução de Danto, Arthur. O abuso da beleza. São Paulo, SP: WMF Martins Fontes, 2015. 
tradição e por uma cultura de conhecedor, quem educa os apreciadores e potenciais compradores de arte moderna?

O processo de educação do público para a arte moderna se dá pela construção de um aparato crítico e teórico por escritores como Zola, Phillipe Burty, Jules Castagnary e Esnest Chesneau 6 . O entendimento se desloca de como interpretar um tema da tradição para a leitura de aspectos formais, como a pincelada e a sinceridade do contato entre o artista e a natureza. Saem de foco os temas da tradição; entra o contato sincero entre a subjetividade do indivíduo e a natureza.

Mas se o mercado já sabe o que esperar de Bouguereau, ou seja, suas belas pinturas rotuladas como "fáceis" e "apelativas" por seus críticos, tal como se esperam sapatos do sapateiro e cervejas do cervejeiro; do artista moderno que se afasta da tradição, no entanto, nada se espera, sua arte é um devir para a qual não há demanda estabelecida. Para ele não há um lugar claro na divisão social do trabalho, ou melhor, há um "não lugar". A profissionalização de uma atividade implica a institucionalização de vínculos entre seus praticantes, a reivindicação de um domínio comum de certas habilidades e a afirmação de critérios de competência. $\mathrm{O}$ artista moderno é um indivíduo isolado em sua produção que, mesmo que faça parte de grupos ou movimentos artísticos, não limita sua criação a normas estabelecidas por uma tradição ou coletividade. Essa individualização parece ser um dos entraves para o estabelecimento de uniões ou cooperativas. Tem-se, então, uma oposição entre o artista isolado em sua produção e suas possibilidades de cooperação profissional.

Ainda que grupos, como os impressionistas, se organizassem em exposições e compartilhassem elementos de estilo, foram raras as tentativas de união entre os artistas com propósitos de sobrevivência material. Van Gogh, como será visto adiante, terá na tentativa de construção de uma coletividade de artistas - e seu fracasso - um elemento central de sua biografia. Por mais contraditório que possa parecer, o artista que serviu como um dos principais modelos de gênio solitário para a posteridade foi, ele próprio, um defensor da produção coletiva e da organização do trabalho por parte dos artistas. 
Há, portanto, uma condição de marginalidade a que o novo artista parece condenado, já que não pertence nem à divisão social do trabalho moderna, nem comunga da racionalidade que a legitima. Jorge Coli assinala que Gustave Courbet foi responsável por criar as bases de uma nova ética artística ancorada na condição marginal do artista ${ }^{7}$, que encontra sua representação mais bem-acabada na obra Bonjour Monsieur Courbet (figura 1). Nela, o artista se retrata como uma espécie de eremita, reverenciado por seu colecionador. O papel de comprador não confere ao patrono uma posição de superioridade, ao contrário, é ele quem reverencia o artista, que se reconhece inferior ao gênio que não pode compreender.

Figura 1 Gustave Courbet, Bonjour Monsieur Courbet, 1854. Óleo sobre tela, $132 \times 150$ $\mathrm{cm}$, Museu Fabré

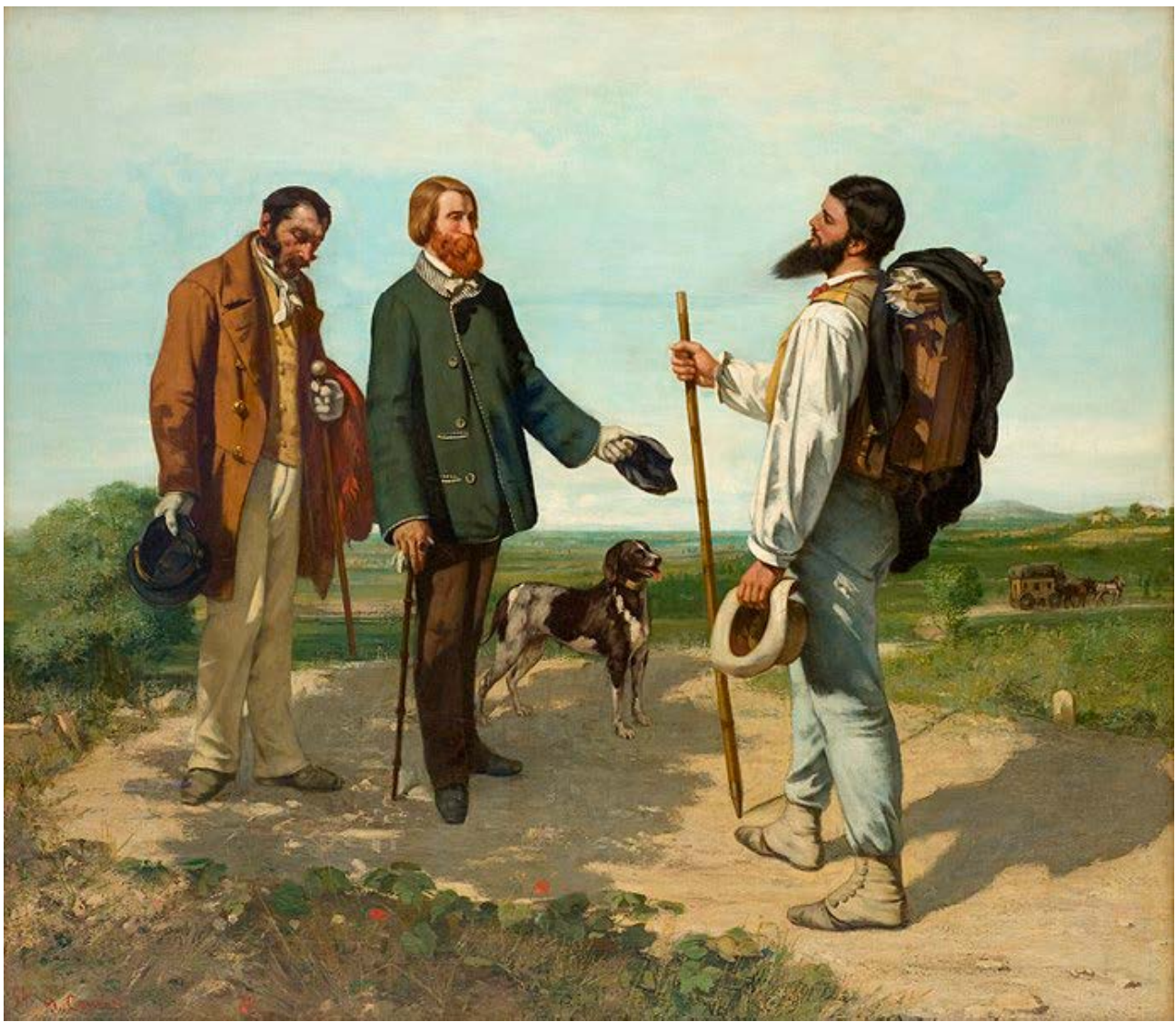

Assim, o "não lugar" ocupado pelo artista é uma condição que dá a ele um status superior em relação ao mero colecionador burguês. É ele quem diz a seu público, olhando de cima para baixo, como sua arte deve ser apreciada,

7 Coli, Jorge. O Corpo da Liberdade: reflexões sobre a pintura do século XIX. São Paulo, SP: Cosac Naify, 2010. p. 152. 
não qualquer critério ancorado na tradição ou nos modelos de imitação do passado. Essa nova ética instaurada por Courbet se propaga aos artistas da segunda metade do século, ainda que se manifeste de modo distinto, como fica claro na releitura (figura 2) que Paul Gauguin faz da mencionada pintura de Courbet, na qual o pintor surge também como alguém isolado, sem contato com o mundo: gênio incompreendido que tudo sacrifica em prol de sua arte. Mas diferentemente de Courbet, Gauguin aparece de modo contido, humilde, como se estivesse afastado da civilização para poder se dedicar plenamente à sua arte, para subir aos montes privilegiados da sensibilidade artística, alcançados somente por alguns indivíduos que pagam um alto preço por isso ${ }^{8}$. $O$ isolamento e o sacrifício são fundamentais na construção da narrativa artística da modernidade.

Em outras palavras, nada seria mais contrário a esse espírito do "novo artista" do que uma colocação precisa na divisão social do trabalho. Assim, ainda que o mercado seja necessário, isto não significa se render ao gosto corrente; significa surpreendê-lo, de algum modo se impor a ele, mesmo que essa imposição só gere frutos tardios ou póstumos.

\section{Van Gogh como arquétipo do artista moderno}

Nesse sentido, a biografia e a carreira de van Gogh surgem como uma espécie de modelo ideal do artista incompreendido, não corrompido pelo mercado, conforme o texto de Holst. Ao passo que, no quadro de Courbet, o artista isolado se impõe, altivo e confiante, a seu colecionador ${ }^{9}$, a biografia de van Gogh traz um sentido de missão, de humilhação perante a sociedade. Courbet se impõe, tanto na pintura acima mencionada quanto em seus autorretratos, nos quais olha de cima para baixo para o espectador; van Gogh não consegue se impor por não ter seu valor percebido por seus contemporâneos. Essa diferença se acentua ainda mais em relação ao mercado.

No caso de Courbet, é o artista que impõe o que deve ser apreciado por seu colecionador, já no caso de van Gogh, o artista, incapaz de ganhar seu

8 Ibid., p. 152.

9 Para uma análise detalhada, ver Coli, Jorge, op. cit., p. 154. 
pão, apesar de merecê-lo, é humilhado por todos aqueles que não podem sentir o que ele está sentindo, nem ver o que ele está vendo. Apesar disso, ele continua sua caminhada, sem "trair os amantes da arte ${ }^{10 "}$ e sem se entregar à vendabilidade. Dito de outro modo, a incompreensão em Courbet é sinal de superioridade imediata e visível; em van Gogh é sinal de humilhação que só será revertida após a morte.

Figura 2

Paul Gau-

guin, Bonjour Monsieur Gauguin, 1889.

Óleo sobre tela, $93 \times 74 \mathrm{~cm}$, Galeria Nacional de Praga

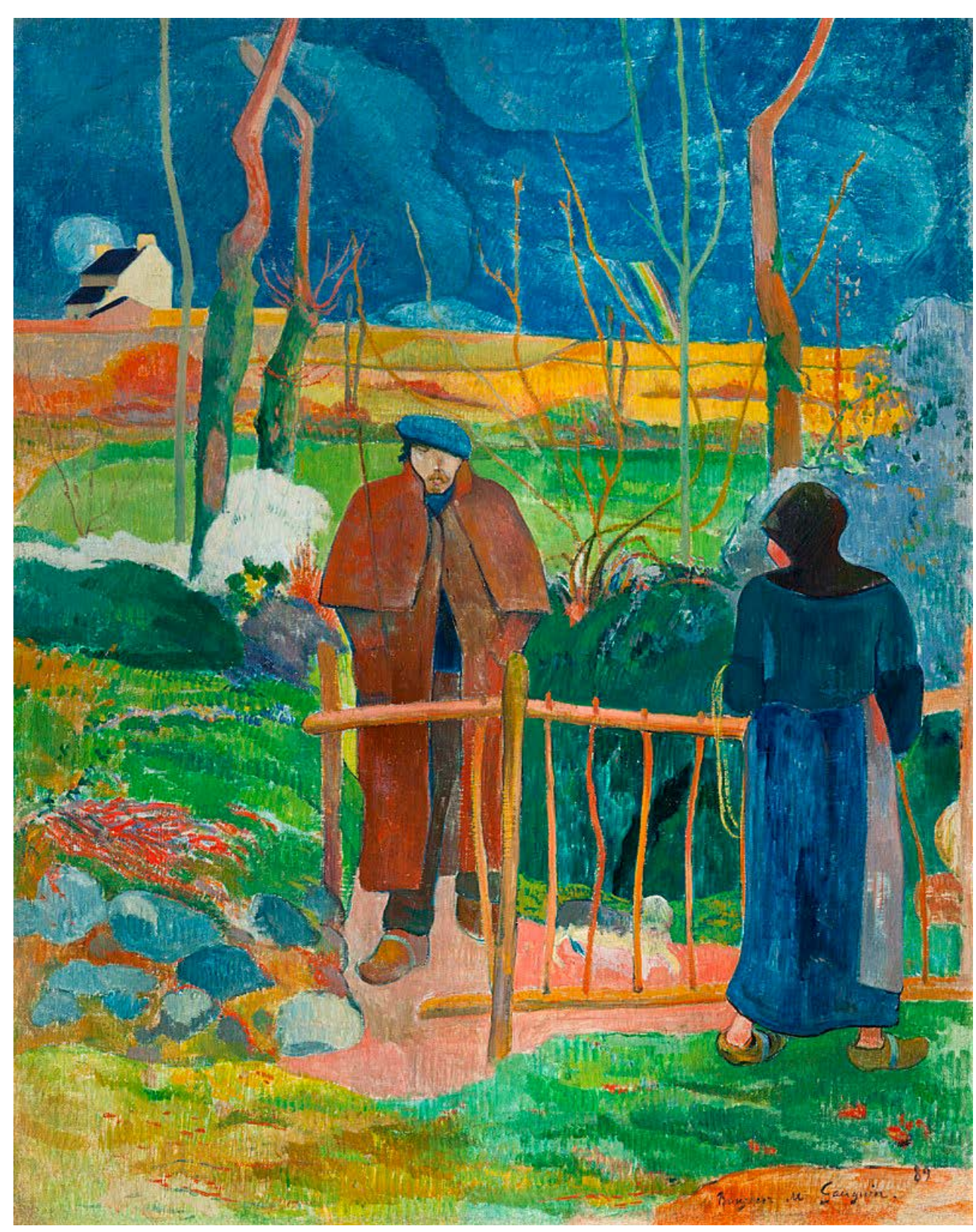

10 Carta 252, enviada por Vincent van Gogh a seu irmão Theo. As cartas podem ser consultadas, obedecendo a numeração mencionada, no site www.vangoghletters.org, traduzidas e comentadas pela equipe de pesquisadores do Van Gogh Museum, em Amsterdã. 
Courbet traçou o terreno da marginalidade dos artistas de vanguarda que o sucederão ${ }^{11}$. Nesse sentido, não só van Gogh, mas também Gauguin e Cézanne vão percorrer, até o final, o caminho aberto pelo mestre francês. Voltemos a obra Bonjour monsieur Gauguin (figura 2). Nela, o pintor aparece clandestino, silencioso, imóvel e surpreso perante a reação da camponesa que a ele dirige olhares de estranhamento, "uma forte solidão emana da obra, a prática da arte exige de Gauguin um isolamento e sacrifícios que Courbet não conheceu"12. De fato, a presença de Gauguin é silenciosa, delicada, quase subalterna. Assim como Courbet, não é compreendido; no entanto, isto não resulta em admiração, mas sim em estranhamento, desprezo, receio. Esse será também o destino de van Gogh, basta lembrar que o pintor holandês foi praticamente expulso da cidade de Arles por seus habitantes - por meio de uma petição endereçada ao prefeito- para perceber como esse estranhamento era real ${ }^{13}$. Depois disso, decidiu se internar no hospício.

Assim, van Gogh dá o primeiro passo, como Courbet - ao não se curvar à vontade do público - mas, diferentemente do francês, não é capaz de impor a esse público aquilo que deve ser aceito como arte. Apesar disso, tem plena consciência da distância entre sua arte e a aceitação do público: ela é mesmo uma prova de superioridade. Uma distância muito maior do que a distância jamais colocada por patronos e pelo mercado a Courbet. Por isso mesmo, o reconhecimento é visto como um mau sintoma pelo pintor holandês. Van Gogh não estava disposto a fazer uma arte para "agradar ao público", ele queria dizer "coisas verdadeiras de um modo áspero", afinal, "a arte era uma batalha na qual devemos dar tudo de nós"14. Esta última frase, curiosamente, foi lida por van Gogh na biografia de Millet, escrita por Alfred Sensier, dentro do contexto dos negócios de Durand-Ruel.

Esse descompasso entre a produção inicial e o reconhecimento posterior, na geração dos artistas do pós-impressionismo, vai atingir o maior espaço já visto: nem antes, nem depois, artistas tiveram que "esperar" a morte para ter seu reconhecimento. É claro que isso não significa que van Gogh,

11 Coli, Jorge. Op cit., p. 154.

12 Ibid.

13 A esse respeito, ver carta 675, enviada a Theo em agosto de 1888.

14 Ver carta 210 e Sensier, Alfred, La vie et l'oeuvre de J. F. Millet, 1882. p. 101. Disponível em: https://archive.org/details/lavieetloeuvrede00sensuoft/page/6. 
Cézanne ou Gauguin não tenham buscado o sucesso e a possibilidade de se manter a partir da venda de suas pinturas, como atestam as correspondências dos três artistas ${ }^{15}$. A questão do trabalho também aparece nas várias pinturas de camponeses e tecelões que o artista pintou quando ainda estava na Holanda. O exemplo mais célebre, Os Comedores de Batatas (figura 3), mostram um trabalho concreto, sem idealizações, muito distante dos camponeses pintados por Millet ou outros nomes da escola de Barbizon. Se os camponeses do francês têm a dignidade do contato com a terra, os camponeses de van Gogh mostram duras feições animalescas, distantes de sua humanidade. Mas se é "feliz aquele que encontrava seu trabalho", para mencionar uma frase de Thomas Carlyle tão citada pelo holandês em suas cartas ${ }^{16}$, como ser feliz quando se é uma extensão da máquina - caso dos tecelões pintados por van Gogh? Ou quando se come a mesma terra que se lavra? - caso de Os Comedores de Batatas (figura 3).

Figura 3

Vincent van Gogh, Os Comedores de Batatas, 1885.Óleo sobre tela, $82 \times 114 \mathrm{~cm}$, Museu Van Gogh, Amsterdã

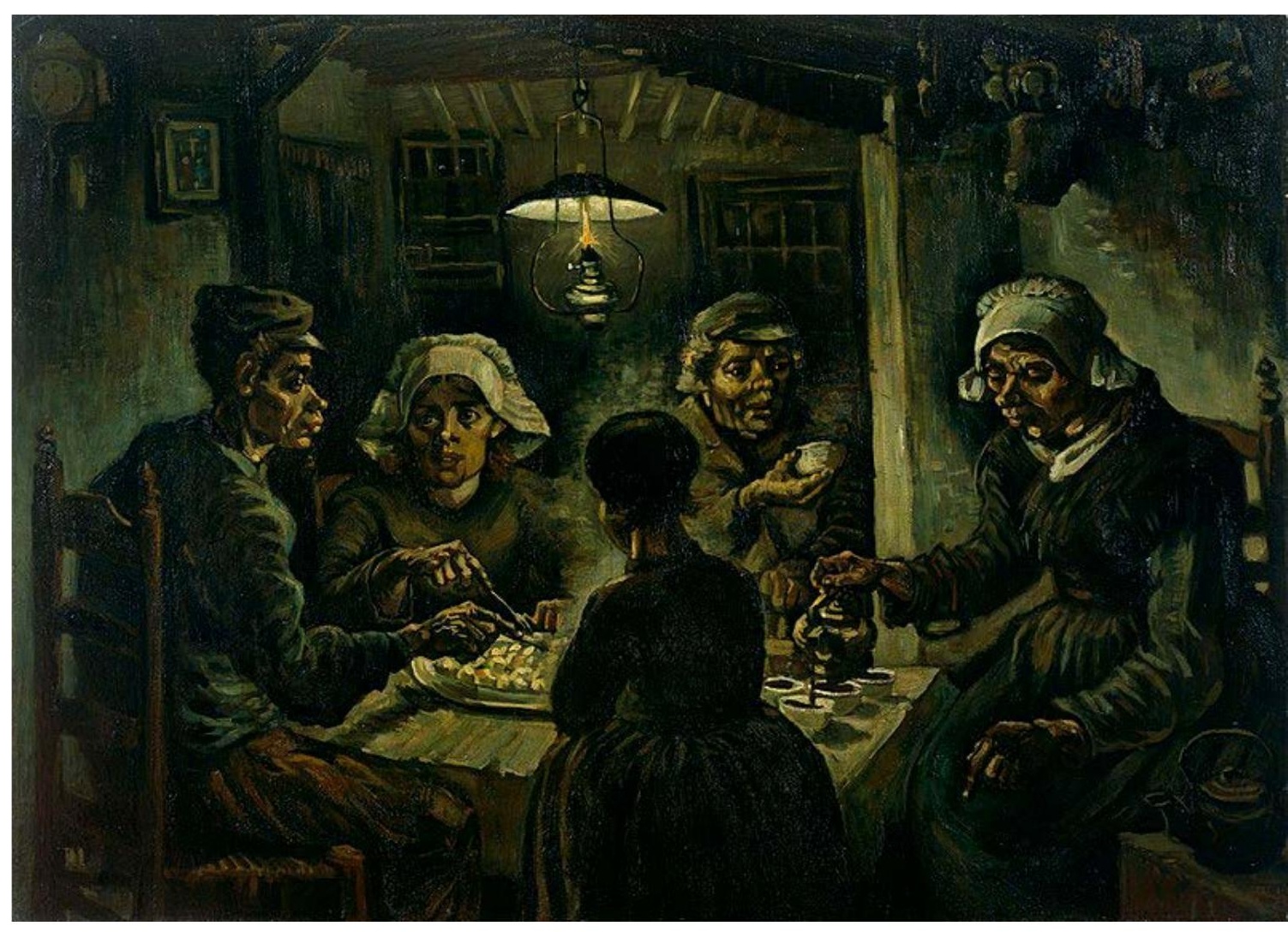

15 Ver Tilborgh, Louis van. Van Gogh Paintings. The Paris period. Vol. 2. Amsterdam: Van Gogh Museum, 1999.

16 A frase de Carlyle está presente em Past and Present e surge em diversos momentos ao longo da correspondência de van Gogh. Ver, por exemplo, a carta 288, enviada em novembro de 1882 . 
A resposta para esta pergunta está no status do trabalho artístico na sociedade industrial. Apesar das dificuldades de um artista, seu trabalho continua a ser um produto de sua subjetividade criadora. Está marcada a diferença entre o artista intelectual e aquele dedicado às artes aplicadas. Nesse sentido, o artista moderno herda do artista tradicional a noção elevada de artista intelectual, longe do mero artesanato. Apesar da miséria material, o artista maldito tem o privilégio de permanecer ligado a seu trabalho, a merecer seu pão, apesar de não o ganhar. Para o artista que trilha o caminho de Courbet, o problema a ser resolvido passa a ser a compatibilização entre esse modo de trabalho e sua sobrevivência.

Apesar disso, autores e artistas imaginaram soluções coletivas para mitigar as dificuldades dos artistas na era capitalista que se consolidava. Fica, porém, uma pergunta: como compatibilizar as soluções coletivas para o trabalho artístico com a individualidade criadora do artista da modernidade? Van Gogh e John Ruskin fazem parte daqueles que imaginaram soluções cooperativas para os artistas no século 19. Nos dois casos, era preciso dar trabalho aos artistas vivos e valorizar menos os artistas já falecidos.

\section{As soluções coletivistas de van Gogh e Ruskin}

Vejamos o sistema de trabalho coletivo pensado porvan Gogh em 1888, a ser realizado em sua Casa Amarela - nome pelo qual ficou conhecido o famoso estúdio do pintor em Arles, sul da França. Antes mesmo de deixar Paris e partir para o sul, van Gogh já tinha imaginado um consórcio de marchands para vender impressionistas que seria encabeçado por seu irmão Theo van Gogh, marchand de reputação sólida, e contaria com agentes distribuídos por diversos países. Pouco depois de chegar a Arles, van Gogh imaginou uma comunidade de artistas que pudesse fazer frente às incertezas da economia de mercado de sua época. Se o chamado Grand Boulevard não podia se aliar ao Petit Boulevard ${ }^{17}$ na construção de um grupo de pintores, que dividiria os riscos da empreitada artística, restava criar uma solução própria: uma comunidade de artistas em Arles, nos moldes do grupo de Pont-Aven, liderado por Gauguin na Bretanha.

17 A distinção entre Grand e Petit Boulevard foi feita pelo artista holandês em 1887. No primeiro grupo estariam os artistas estabelecidos e que já obtinham reconhecimento, como Monet e Renoir, no segundo, os artistas do chamado pós-impressionismo, como Gauguin, Seurat e o próprio van Gogh. Ver carta 584. 
Os artistas dessa comunidade viveriam como monges sob a liderança de um membro superior ${ }^{18}$, "naturalmente Gauguin". Sua produção seria organizada a partir de uma colaboração que envolveria não só uma divisão de lucros, mas também de custos. Desse modo, os artistas, trabalhando em conjunto, formariam uma espécie de cooperativa, evitando a concorrência e criando um ambiente de prosperidade coletiva. Isto, é claro, não implicaria renunciar à própria individualidade. Ao contrário: do ponto de vista estético, essa colaboração se daria à medida que as obras complementassem umas às outras. Os pintores seriam capazes de preservar sua individualidade criativa, formando uma aliança estética e material, como van Gogh explica em carta a Emile Bernard ${ }^{19}$.

Assim, segundo o pintor holandês, essa comunidade teria o mérito de ser parte de uma constelação criativa, a exemplo dos "escultores gregos", dos "músicos alemães" e dos "romancistas franceses"20. Ou mesmo uma nova Guilda de São Lucas. Esta última aproximação desloca a questão definitivamente para o mundo do trabalho. Não se trata somente de uma afirmação de caráter artístico, mas também remonta a uma forma de organização do trabalho, que se opunha diretamente ao trabalho industrial.

As obras deixariam o circuito das galerias e migrariam para um território independente do mercado, sem com isso condenar o artista à fome. Seu ponto de partida seria Theo, responsável por uma ajuda inicial e pelo escoamento da produção. O marchand aparece, portanto, como uma engrenagem adicional para o funcionamento desse mecanismo e não como seu motor propulsor. A importância está mais na pessoa de Theo do que em sua função como marchand. A criação dessa espécie de associação derivada do Petit Boulevard está baseada em uma ideia de produção cooperativa, fundada na união dos trabalhadores de modo a garantir a sobrevivência e a produção de sua arte. Seria correto, então, supor que marchand e artista, neste caso, assumiriam o papel de patrono e artista, como no passado? Não, neste caso, o marchand assumiria o papel de um colaborador do negócio artístico, não alguém interessado em seu próprio benefício, mas membro de uma espécie de comunidade, de fraternidade "espiritual", para além da racionalidade dos negócios do mundo capitalista.

18 Carta 694, enviada a Theo em outubro de 1888. Do original: "naturellement cela serait Gauguin".

19 Carta 634, enviada a Bernard em julho de 1888.

20 Carta 622, enviada a Bernard em junho de 1888. 
Desse modo, o trabalho artístico voltaria a um estágio pré-capitalista; um ambiente cooperativo capaz de romper com os expedientes de venda de biografias comuns a partir da segunda metade do século. Por isso as soluções coletivas são importantes, já que elas dão conta não somente das questões diretamente materiais, mas nublam as possibilidades de venda de temperamentos, de indivíduos isolados. Formulações cooperativas para a produção de obras de arte, como a de van Gogh, não eram novidade. Basta pensar nas ideias de William Morris, ou mesmo em Carlyle que defendeu o trabalho cooperativo a exemplo das práticas medievais ${ }^{21}$. O traço comum entre esses movimentos era uma espécie de fuga romântica para resolver os problemas materiais de sua época.

Em suas conferências sobre a Economia Política da Arte, John Ruskin apontou a necessidade de não esperar que os artistas morressem para que fossem finalmente valorizados ${ }^{22}$. Entretanto, o mercado de arte moderna não remunerava os artistas diretamente, mas antes um complexo sistema que envolvia a crítica, os marchands e as instituições. Por isso mesmo, o negócio artístico torna-se mais lucrativo quanto mais seja composto efetivamente de artistas mortos - ou que tenham vivido tempo suficiente para a construção de uma biografia compatível com os expedientes de venda da época.

Tomemos o exemplo do Angelus de Millet (figura 4), vendido em 1889 por 750 mil francos. Quando saiu do ateliê do artista, na década de 1860, rendeu a quantia módica de 1600 francos ao pintor. Antes de sua venda estrondosa, a pintura havia mudado de mãos seis vezes e seu preço já estava muito distante do valor recebido por seu criador. Mais que isso, a pintura de Millet passou a valer mais justamente porque ele estava morto - nesse estágio do mercado, a biografia completa acrescenta valor à obra. Era o melhor exemplo possível para evocar as injustiças do comércio de artistas mortos que, inclusive, ameaçava a própria produção de arte contemporânea.

21 William Morris foi o principal idealizador do movimento Arts and Crafts. Entre outras coisas, esse movimento pregava uma volta ao trabalho artesanal, nos moldes das corporações de ofício medievais. A arte produzida também teria um caráter utilitário, estaria presente no cotidiano, na decoração das casas e nos objetos utilizados pelas pessoas. Assim, seu sistema de trabalho estaria distante do mundo industrial, impessoal. Suas ideias influenciaram movimentos como a Irmandade Pré-Rafaelita. Para aprofundar a questão, recomendo a leitura de Skoblow, J. The writings of William Morris (1834-1896). In: E. Prettejohn (ed.). The Cambridge Companion to the Pre-Raphaelites. Cambridge Companions to Literature, 2012. p. 196-210.

22 Ruskin, John. A economia política da arte. Rio de Janeiro, RJ: Record, 2004. 
Figura 4

Jean-François Millet, Angelus. Óleo sobre tela, $55 \times 66 \mathrm{~cm}$, Museu d'Orsay

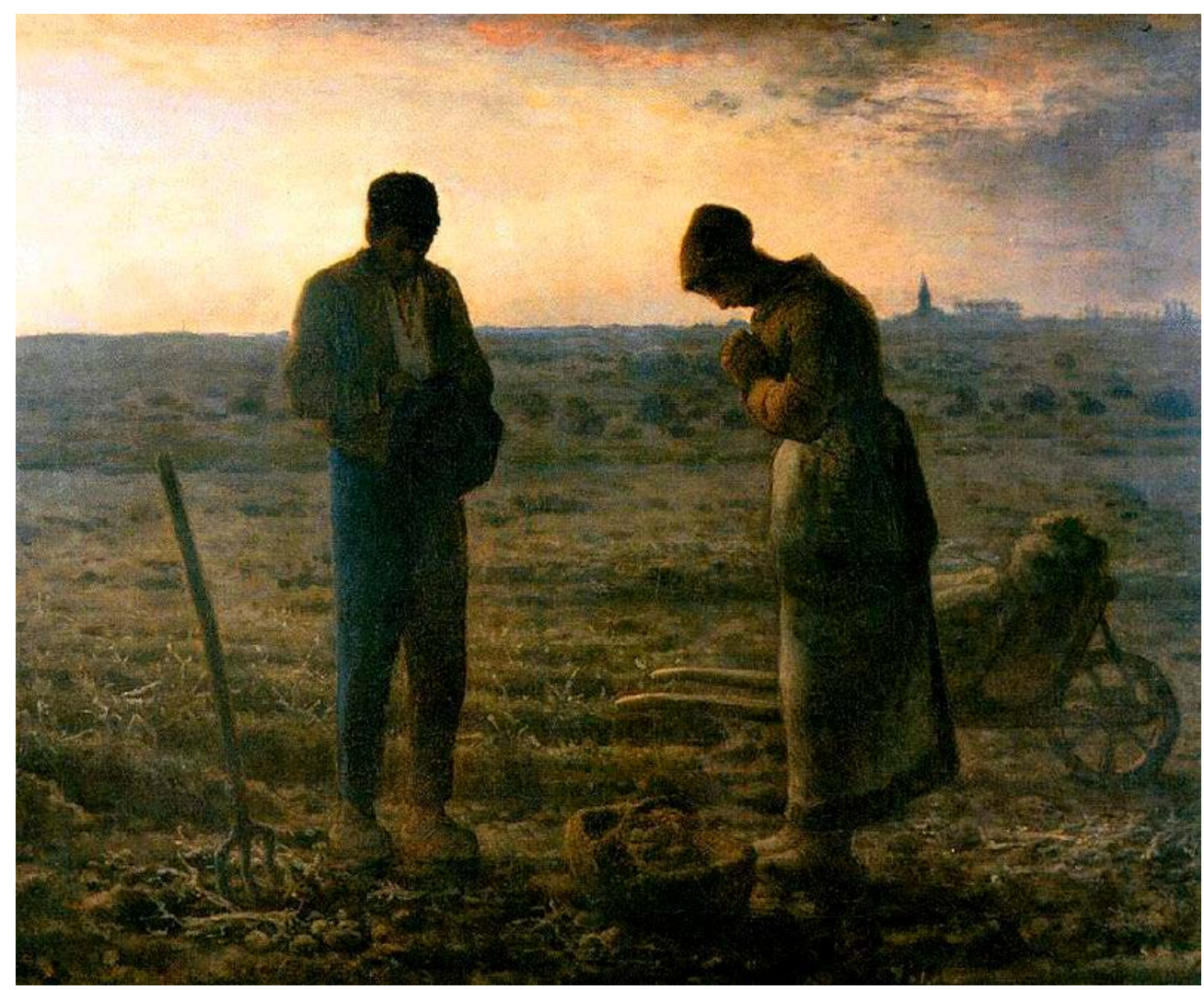

No contexto de uma economia nacional, Ruskin alertava que, ao se comprarem obras de artistas mortos, esquece-se dos vivos que precisam dos honorários relativos às suas obras para poder continuar produzindo. Em outras palavras, financiar os artistas vivos era uma questão de importância nacional, na medida em que mantinha a circulação da cultura. Era preciso que alguém comprasse o que estava sendo produzido: as obras necessitavam circular e chegar às mãos dos compradores e remunerar os produtores ${ }^{23}$. Mas Ruskin também condenou os altos valores pagos por artistas vivos: "creio que os preços pagos por quadros modernos são um dos principais obstáculos ao desenvolvimento da arte moderna". Segundo o autor, o atrativo da riqueza serviria somente para deturpar o trabalho do artista e o empurraria na direção de esforços para agradar a opinião pública ${ }^{24}$. Desse modo, a solução pretendida por Ruskin passa não somente pela remuneração justa dos artistas, mas também por tornar a produção de obras de arte uma questão de importância nacional. 
Com efeito, este é também um problema de distribuição, para o qual Ruskin propõe uma participação maior do Estado. O Estado seria o ente responsável por manter os pintores trabalhando por um valor digno, capaz de sustentar sua existência como artistas e não escravizar seu espírito. Para isso também se articulariam as obras públicas e os edifícios, como escolas e prédios que absorveriam a produção dos artistas. No limite, Ruskin defendia que o Estado controlasse a produção e a distribuição de arte, limitando a ação do mercado. Ironicamente, esta solução está muito próxima do sistema acadêmico francês que, ao final do século, era incapaz de lidar com a dinâmica do mercado de arte moderna. Em outras palavras, segundo o autor, deixar a arte ao sabor do mercado seria mesmo prejudicial ao futuro do que ele chama de "boa arte". Os mecanismos de mercado fariam uma espécie de "seleção adversa", criando um abismo entre aqueles pintores que caíram nas graças do alto mercado e aqueles que mal conseguiam se sustentar ${ }^{25}$.

Na prática, o autor propõe uma regulação do mercado pelo Estado, de modo que o pagamento fosse depositado nas mãos de artistas vivos em vez de ser vertido ao caixão. Nesse contexto, Ruskin considera o marchand como alguém prejudicial à arte, responsável por jogar o artista no estômago do mercado sem grande preparo. É claro que Ruskin percebeu que o negócio da arte moderna tinha pouco a ver com a remuneração do artista e a sobrevivência da própria arte, mas sim com um circuito de valorização próprio - que passava pelo mercado financeiro - e remunerava variados agentes nem sempre conectados com o mundo artístico: um negócio capitalista, como qualquer outro. Assim, tanto a solução de van Gogh quanto a de Ruskin propunham uma recusa do mercado e, com isso, da venda de temperamentos. Se o pintor holandês imaginava cooperativas, Ruskin pedia mais Estado e menos mercado. Nos dois casos, o objetivo final dessa organização seria a manutenção da produção da arte e não o lucro do empreendimento artístico e dos artistas.

Mas o mercado de arte, tal qual estruturado no século 19, tinha profundas ligações com o mercado financeiro e com os mecanismos de valorização de riqueza da época. Além disso, ele estava assentado na individualidade criativa. Dada a própria natureza do trabalho artístico, nada seria mais estranho a este mercado do que a produção coletiva, fosse nos moldes 
pensados por van Gogh, fosse nos moldes pensados por Ruskin. Mais do que nunca, a arte precisava ser filtrada pelo temperamento, pela personalidade artística, para se tornar uma mercadoria no sentido moderno, algo distante das iniciativas aqui mostradas, a despeito das melhores intenções de van Gogh com seu estúdio em Arles. O próprio exemplo de van Gogh no mercado é prova disso, sobretudo após sua morte, quando os preços de seus quadros dispararam. Sua biografia atormentada e sua incapacidade de vender foram elementos fundamentais dessa valorização póstuma.

Dito de outro modo, as iniciativas propostas por Ruskin e por van Gogh não eram viáveis dadas as características fundamentais do mercado de arte moderna. Isso significa que as obras de arte estavam cada vez mais ligadas ao temperamento dos artistas que as tinham concebido. No caso de van Gogh, esse exemplo salta aos olhos mais do que em qualquer outro artista. Ironicamente, enquanto ele pensava em soluções coletivas e rejeitava a exclusão do artista indivíduo da divisão social do trabalho, sua biografia, calcada no isolamento trágico e na individualidade criativa, foi fundamental para seu fortalecimento póstumo no mercado. Isso retoma o que foi colocado ao longo deste artigo: é fundamental para o mercado de arte moderna rejeitar sua própria característica comercial ou, pelo menos, deixá-la em segundo plano. Van Gogh é prova de que este mercado precisa negar a si próprio para poder afirmar ao máximo seu potencial de valorização.

\section{Referências}

ASHENFELTER, Oerley e GRADDY, Kathryn. Auctions and the Price of Art, Journal of Economic Literature, v. XLI, p.763-786, 2003.

BÄTSCHMANN, Oskar. The Artist in the Modern World: The Conflict between Market and Self-Expression. New Haven: Yale University Press, 1997. BOIME, Albert. Enterprise and Entrepreneurs in Nineteenth and Twentieth-Century France, ed. Edward Carter et al. (Baltimore and London: Johns Hopkins University Press, 1976.

CABANNE, Pierre. Van Gogh. Lisboa: Verbo, 1985.

CLARK, T. J. The Painting of Modern Life: Paris in the Art of Manet and His Followers. New York: Knopf, 1985.

COLI, Jorge. O Corpo da Liberdade: reflexões sobre a pintura do século XIX. São Paulo, SP: Cosac Naify, 2010.

DURAND-RUEL, Paul; DURAND-RUEL, Flavie. Paul Durand-Ruel: memoirs of the first impressionist art dealer. Paris: Flammarion, 2014. 
FEILCHENFELDT, Walter. VINCENT VAN GOGH: The Years in France: Complete Paintings 1886-1890. 348 pages. 4to, cloth. London, Philip Wilson, 2013. FLETCHER, Pamela; HELMREICH, Anne. The Rise of the Modern Art Market in London 1850-1939 Manchester University Press, 2011.

GOGH, Vincent van. The Complete Letters of Vincent van Gogh, Londres: Thames and Hudson, 1978.

GREEN, Nicholas. "Circuits of Production, Circuits of Consumption: The Case of Mid-Nineteenth-Century French Art Dealing", Art Journal, Vol. 48, No. 1, Nineteenth-Century French Art Institutions (Spring, 1989).

GREEN, Nicholas. "Dealing in Temperaments: Economic Transformation of the Artistic Field in France during the Second Half of the Nineteenth Century". Art History 10, March 1987.

HARVEY, David. Paris, a capital da modernidade. São Paulo: Boitempo, 2015. HEINICH, Nathalie. Glory of Van Gogh: An Anthropology of Admiration, Princeton Univ. Press. 1996.

JENSEN, Robert. GALENSON, David, "Careers and Cavnases: The Rise of the Market for Modern Art in Nineteenth-Century Paris", in: Van Gogh Studies. Amsterdam: Van Gogh Museum 2007: 136-166.

JENSEN, Robert. Marketing Modernism in Fin-de-Siècle Europe. Princeton: Princeton University Press, 1994.

KINDLEBERGER, Charles. A Financial History of Western Europe. Londres: George Allen \& Unwin, 1984.

REWALD, John. Studies on Post-Impressionism, Londres: Thames and Houdson, 1986.

REWALD, John. The History of Impressionism. London: Secker \& Warburg, 1973.

RUSKIN, John. A economia política da arte. Rio de Janeiro, RJ: Record, 2004. WHITE, Cynthia A.; WHITE, Harrison C. Canvases and Careers, Institutional Change in The French Painting World. Chicago: University Chicago Press, 1993.

Recebido em 19 de abril de 2020 e aceito em 06 de junho de 2020.

Este é um artigo publicado em acesso aberto sob uma licença Creative Commons (cc)) 